\title{
Timing of stagnation of Ice Stream G, West Antarctica, from short-pulse radar studies of buried surface crevasses
}

\author{
RoRy RetZlafF and CHaRles R. Bentley \\ Geophysical and Polar Research Center, University of Wisconsin-Madison, Madison, Wisconsin 53706, U.S.A.
}

\begin{abstract}
Five short-pulse radar profiles were run across the edge of inactive Ice Stream C, one of the "Ross" ice streams that flows from the West Antarctic inland ice sheet into the Ross Ice Shelf. Scatter from buried crevasses, which we presume were at the surface of the ice stream when it was active, creates hyperbolae on the radar records. A density-depth curve and local accumulation rates were used to convert the picked travel times of the apices of the hyperbolae into stagnation ages for the ice stream. Stagnation ages are $130 \pm 25$ year for the three profiles farthest downstream and marginally less $(100 \pm 30$ year $)$ for the fourth. The profile farthest upstream shows a stagnation age of only $\sim 30$ year. We believe that these results indicate a "wave" of stagnation propagating at a diminishing speed upstream from the mouth of the ice stream, and we suggest that the stagnation process involves a drop in water pressure at the bed due to a conversion from sheet flow to channelized water flow.
\end{abstract}

\section{INTRODUCTION}

Ice streams A, B, D and E (Fig. 1) carry the preponderance of the ice that flows from West Antarctica into the Ross Ice Shelf. Ice Stream C is anomalous in that today it is nearly stagnant; it moves at only $1-10 \mathrm{~m} \mathrm{year}^{-1}$ compared to $\sim 450 \mathrm{myear}^{-1}$ for adjacent Ice Stream B (Whillans and others, 1987; Whillans and Van der Veen, 1993a). Flights over Ice Stream C revealed no visual sign of the surface crevasses found throughout an active ice stream, yet the radar-sounding records show scatter typical of other ice streams (Robin and others, 1970; Rose, 1979) and the shear margins are well defined and easily correlated (Shabtaie and Bentley, 1987). The source of this scattering is buried crevasses that presumably were at the surface when Ice Stream $\mathrm{C}$ was active.

A short-pulse radar experiment was performed during the 1988-89 Antarctic field season, as part of the University of Wisconsin's Glaciogeophysical Survey of the Interior Ross Embayment (GSIRE), to determine the stagnation chronology for Ice Stream $\mathrm{C}$ from the burial depths of crevasses along its shear margin. Previous measurements of the depths to buried crevasses in the center of the ice stream led Bentley and others (1985) to estimate that the ice stream stagnated, i.e. ceased motion rapid enough to keep crevasses active, about 250 years ago. However, crevasses are commonly buried within active ice streams - in the vicinity of Upstream B camp on Ice Stream B, e.g. Bentley and others (1985), so that age had to be considered a maximum. Shear margins of active ice streams are characterized by a heavy concentration of exposed crevasses caused by the extreme stresses that must exist there so long as the ice stream remains active. Consequently, the burial time of the marginal crevasses along Ice Stream C should be a good measure of the time since the ice stream stagnated. We implicitly equate those two times throughout this paper.

The experiment comprised five profiles across the shear margin on to Ridge BC (Fig. 1). The profiles were distributed along the ice stream to ascertain how the stagnation time varied from its head to its mouth.

\section{INSTRUMENTATION}

A GSSI Model SIR8 mono-pulse radar system operating at a center frequency of $80 \mathrm{MHz}$, with an applied peak power of $42 \mathrm{~W}$, a pulse-repetition rate of $25.6 \mathrm{scans} \mathrm{s}^{-1}$ and a pulse duration of $6 \mathrm{~ns}$, was used. The radar system and operator, mounted on a Nansen sled, and the antenna, mounted on skis, were towed by an Elan snowmobile. Traveling speeds varied irregularly but were on the order of $2 \mathrm{~m} \mathrm{~s}^{-1}$. The data were recorded (unfortunately, owing to an equipment failure, only in analog form) using a Biosonics Model N115 portable chart recorder. Distance along the surface was estimated from the rotations of a mechanical wheel attached to the sled combined with elapsed time. Positioning errors resulting from an uneven speed of travel could be tens of meters but precise positioning was not required for these experiments. Transportation to experiment sites was by Twin Otter aircraft flown under contract with the U.S. National Science Foundation by Ken Borek Air, Ltd. Positions for 


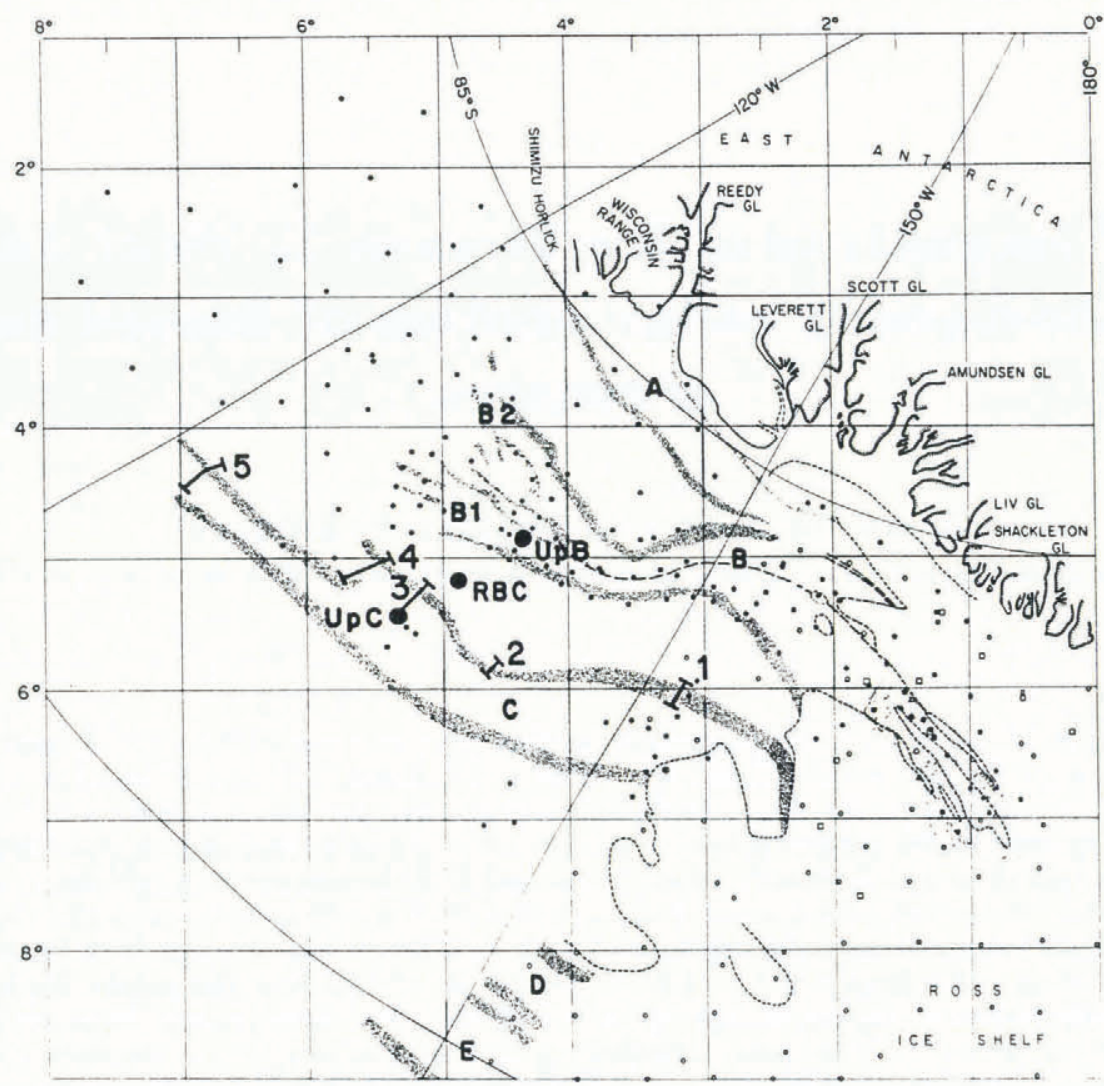

Fig. 1. Map showing the location of the five profiles (numbered 1-5) across the shear margin of Ice Stream $C$. The ice streams are labeled $A, B(B 1, B 2)$ and $G$. $U p B, R B C$ and $U p C$ camps are denoted by heavy solid circles. Surface stations of the Siple Coast Project (solid circles), RIGGS (open circles) and the IGY Ross Ice Shelf traverse (open squares) are shown. Grounding lines are shown by short-dashed lines. The long-dashed line is the boundary between confluent Ice Streams B1 and B2. Glaciers flowing from the Transantarctic Mountains are shown to the south. The origin of the rectangular grid coordinate system used on this and subsequent maps is at the South Pole; grid north is toward Greenwich and therefore toward the top of the map. Squares are $1^{\circ}$ of latitude on a side. This map is a modified version of the one presented by Shabtaie and Bentley (1988).

the starting and ending points of each profile were taken from the inertial navigation system of the Twin Otter aircraft.

\section{THE EXPERIMENT}

\section{Data reduction}

Snow-accumulation rates used in converting burial depths to times since ice-stream stagnation were taken from regional maps of accumulation (see Table 1). From Whillans and Bindschadler (1988), we take $\pm 15 \mathrm{~kg}$ $\mathrm{m}^{-2} \mathrm{year}^{-1}$ as the error estimate in the accumulation rate.

A $10 \mathrm{~m}$ ice core taken by glaciologists from the Ohio State University (OSU) at the starting point of each profile was intended to supply an accumulation rate. Unfortunately, due to the poor quality of the recovered cores, accumulation rates were determined only from profiles 2 and 4 . At both sites, the indicated accumulation, recently obtained, was about $10 \mathrm{~kg} \mathrm{~m}^{-2} \mathrm{year}^{-1}$ (personal communication from M. Jackson, 1992). The difference between these rates and those we used (Table $1)$ is within our error estimate.

Density-depth curves (Fig. 2), used to determine the radio-wave velocities needed to convert reflection times to burial depth, were obtained from the ice-core analysis of
Alley and Bentley (1988) at UpB and Ridge BC (RBC) camps and were also calculated from the short-refraction seismic experiments at those sites and at UpC camp (Fig. 1). Comparison of the seismic results with the measured

Table 1. Accumulation rates and their sources for "shearmargin" profiles

$\begin{array}{ccc}\text { Profile } & \begin{array}{c}\text { Accumulation rate } \\ \mathrm{kg} \mathrm{m}^{-2} \text { year }^{-1}\end{array} & \text { Source } \\ & & \\ 1 & 7 & 1,2 \\ 2 & 8 & 3 \\ 3 & 9 & 4 \\ 4 & 11 & 4 \\ 5 & 15 & \end{array}$

Sources: 1. Clausen and others (1979, fig. 1). 2. Shabtaie and Bentley (1987, fig. 16). 3. Interpolation between profiles 1 and 3; extrapolation of trend seen in source 4 . 4. Whillans and Bindschadler (1988, fig. 3). 


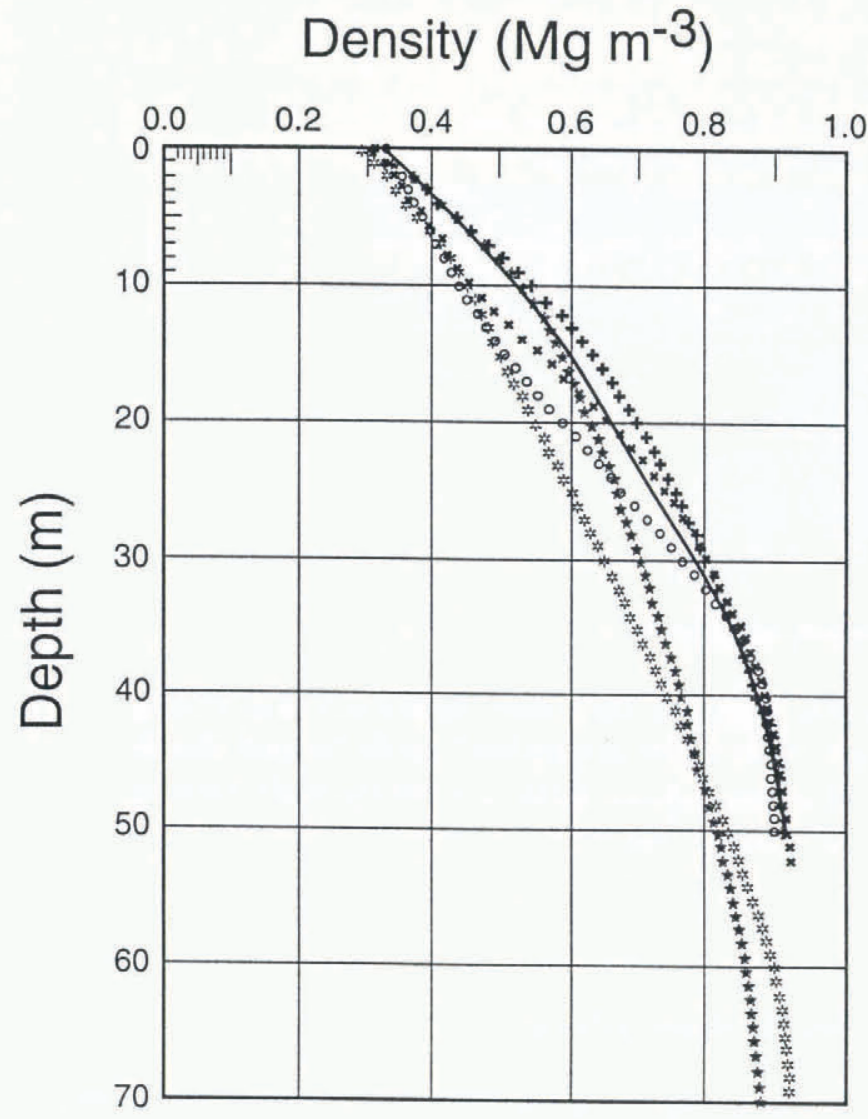

Fig. 2. Plots of density vs depth as measured on ice cores from $U p B$ (+ signs) and $R B C$ (stars), and as calculated from seismic measurements at $U p B$ (xs), $R B C$ (sun bursts) and $U p C$ (circles). The solid line is the "corrected" curve for UpC.

densities at $\mathrm{UpB}$ and $\mathrm{RBC}$ indicates that the seismic method underestimated the densities there by as much as $20 \%$ in the upper $30-40 \mathrm{~m}$. Why this should be true, we do not know; densities calculated from seismic velocities generally provide a much better fit than that to measured densities (Kohnen, 1972; Kirchner and others, 1979). (Fortunately, as we shall see, the uncertainty in density has only a small effect on the calculated depths.)

We can correct the calculated densities for $\mathrm{UpC}$ by comparison with the measurements at the other two sites. We may take $\mathrm{UpB}$ and $\mathrm{RBC}$ as typical of high-stress and low-stress environments, respectively - the more rapid increase of density with depth at $\mathrm{UpB}$ (a consequence of the non-linearity of the densification equation-see, e.g. Crary and Wilson, 1961) is evident (Fig. 2). At UpC, the environment presumably changed from high stress to low stress when the ice stream shut down, as shown by the fact that the densities calculated from the seismic velocities at $\mathrm{UpC}$ follow the corresponding curve for RBC down to a depth of about $15 \mathrm{~m}$, then, over the next $20 \mathrm{~m}$, increase rapidly to join the higher-density UPB curve. We assume that the real densities show the same trend; this leads to the corrected density-depth curve shown in Figure 2 for UpC, which correspondingly follows RBC densities to $15 \mathrm{~m}$ and then increases rapidly in density to join the $\mathrm{UpB}$ curve below $35 \mathrm{~m}$.

The corrected UpC density-depth curve was combined with Looyenga's (1965) equation $\epsilon_{\mathrm{f}}^{\frac{1}{3}}-1=\rho_{\mathrm{f}} / \rho_{\mathrm{i}}$

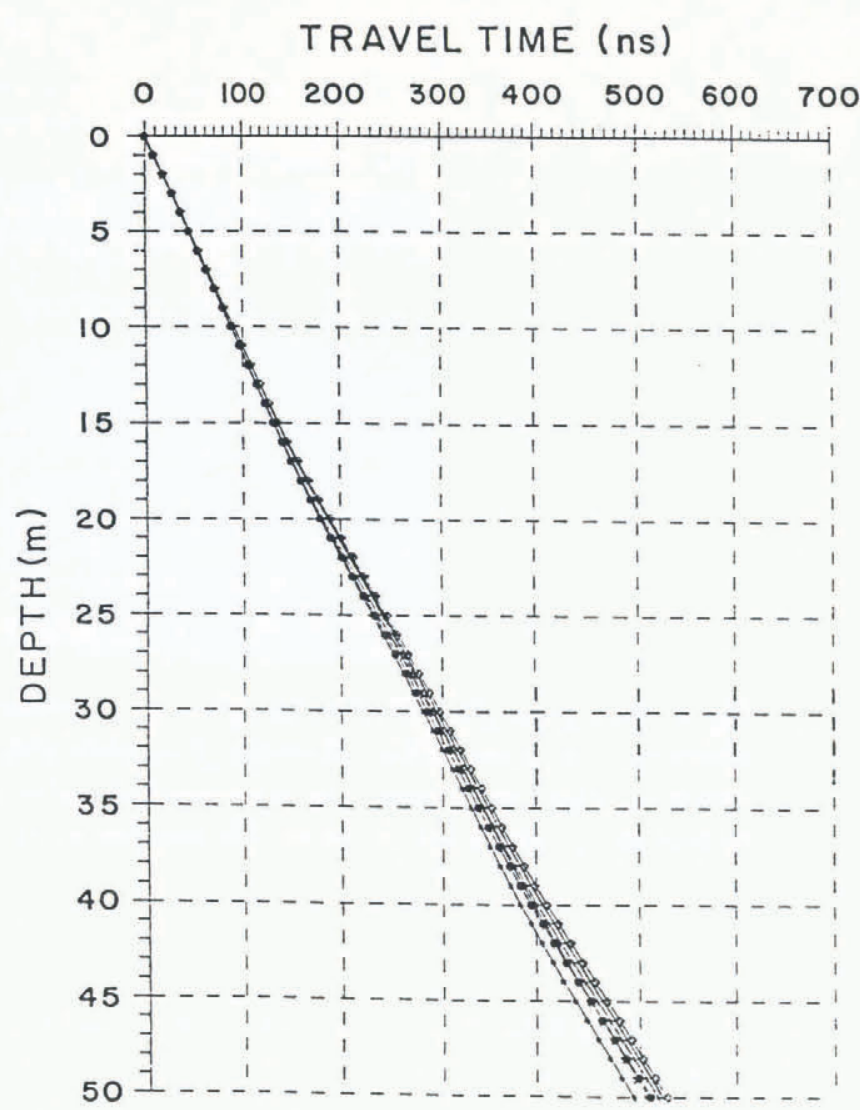

Fig. 3. Plots of two-way travel time vs depth for the six density-depth curves shown in Figure 2. The "corrected" curve for $U p C$ is shown by the line without symbols between the lines with the two different plus signs. The important point is that the curves are virtually indistinguishable.

$\left(\epsilon_{\mathrm{i}}^{\frac{1}{3}}-1\right)$, where $\rho_{\mathrm{i}}=$ solid-ice density $=917 \mathrm{~kg} \mathrm{~m}^{-3}$, $\rho_{\mathrm{f}}=$ firn density, $\epsilon_{\mathrm{i}}=$ dielectric constant of solid ice $=$ 3.17 and $\epsilon_{\mathrm{f}}=$ dielectric constant of the firn, to obtain the variation of the dielectric constant of the firn with depth. Next, a velocity-depth curve was constructed using $v=c / \epsilon_{\mathrm{f}}^{\frac{1}{2}}$, where $v=$ velocity of radio waves in the firn and $c=$ speed of light $\left(300 \mathrm{~m} \mu \mathrm{s}^{-1}\right)$. Finally, the velocitydepth curve was in turn used to produce a curve of twoway travel time vs depth (Fig. 3) from which travel times were converted to true depths. Similar curves derived for the five other sets of density-depth data (cores at UpB and $\mathrm{UpC}$; uncorrected short-refraction data at $\mathrm{UpB}$, $\mathrm{RBC}$ and $\mathrm{UpC}$ ) show that for the burial depths with which we are concerned ( $30 \mathrm{~m}$ or less) the variation in the depth calculated from the different density-depth curves is only $\pm 1 \mathrm{~m}$ (Fig. 3 ). It seems unlikely that the densitydepth curves anywhere along the margin of Ice Stream C would lie significantly outside the limits represented by the "pure ice-stream"-type curve of UpB and the "pure ridge"-type curve represented by $\mathrm{RBC}$, so we adopt $\pm 1 \mathrm{~m}$ as the depth error from this source for all five sites.

The depth to a scattering source, presumably the angular edge of a buried crevasse, can be determined by picking the two-way travel time to the apex of the hyperbola generated by the source (Fig. 4). The sources of scatter within the shear margin are numerous, so the hyperbolae are very densely distributed, generally overlying one another. Every $100 \mathrm{~m}$ along each profile the 


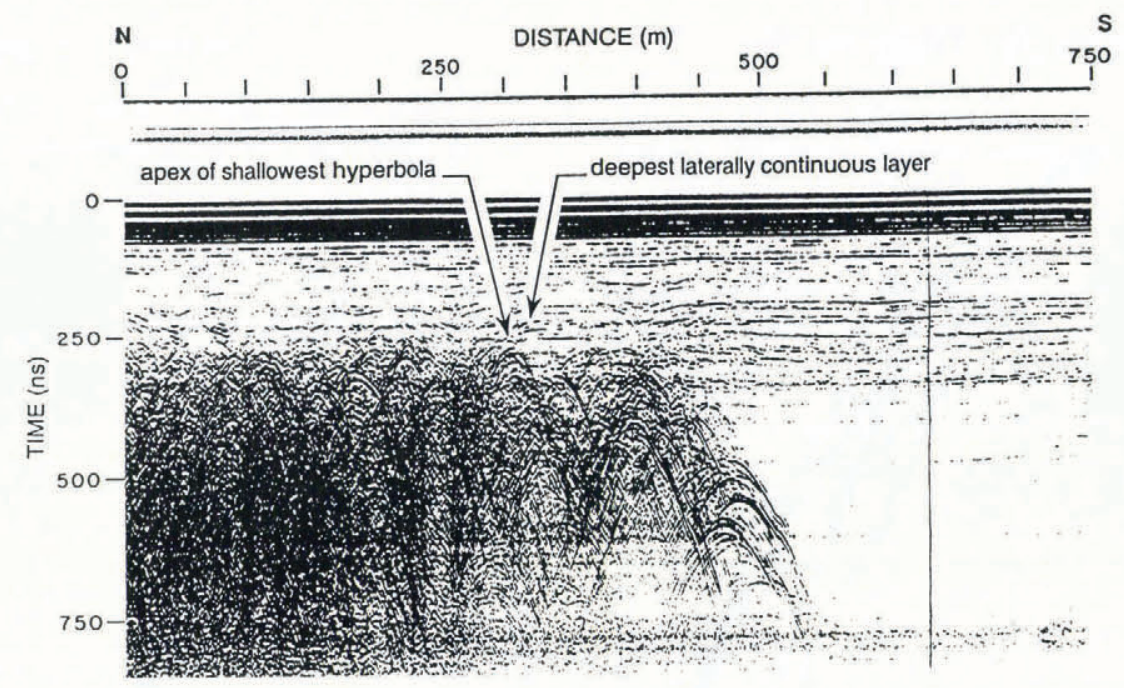

Fig. 4. Radargram of a part of profile 1 from the shear margin on to Ridge BC. The surface, the first of a series of heavy horizontal lines, is marked 0 ns. Examples of our picks of the "apex of the shallowest hyperbola" and the "deepest laterally continuous layer" are marked. The dense hyperbolae at about 250 ns drop to greater depths and then end at the transition between the ice stream and the ridge. The direction of ice flow is out of the page.

travel time was picked, with an accuracy of about $20 \mathrm{~ns}$, to the deepest laterally continuous layer and also to the apex of the shallowest hyperbola (see example in Figure 4); the difference between them was used as a measure of the uncertainty in picking the burial depth. Both sets of travel times were converted to depths and plotted (Figs 58) along with age-depth scales that were established for each of the profiles by combining the accumulation rate with the density-depth curve. Due to compaction in the firn, the age is not linear with depth and ages at a given depth differ from site to site owing to different accumulation rates.

\section{Profile descriptions}

Profile 1 (Fig. 5), from Ice Stream C on to Ridge BC at the downstream end of the ice stream, shows a burial depth that becomes gradually shallower along the first $4 \mathrm{~km}$ of the profile and then remains constant to the abrupt end of the shear zone at $20 \mathrm{~km}$. The point where the depths become constant, and the point where the crevasses end, correlates closely with the inner and outer boundaries of the shear margin, respectively, as mapped by Shabtaie and Bentley (1987). The greater depths of burial within the ice stream probably means that those
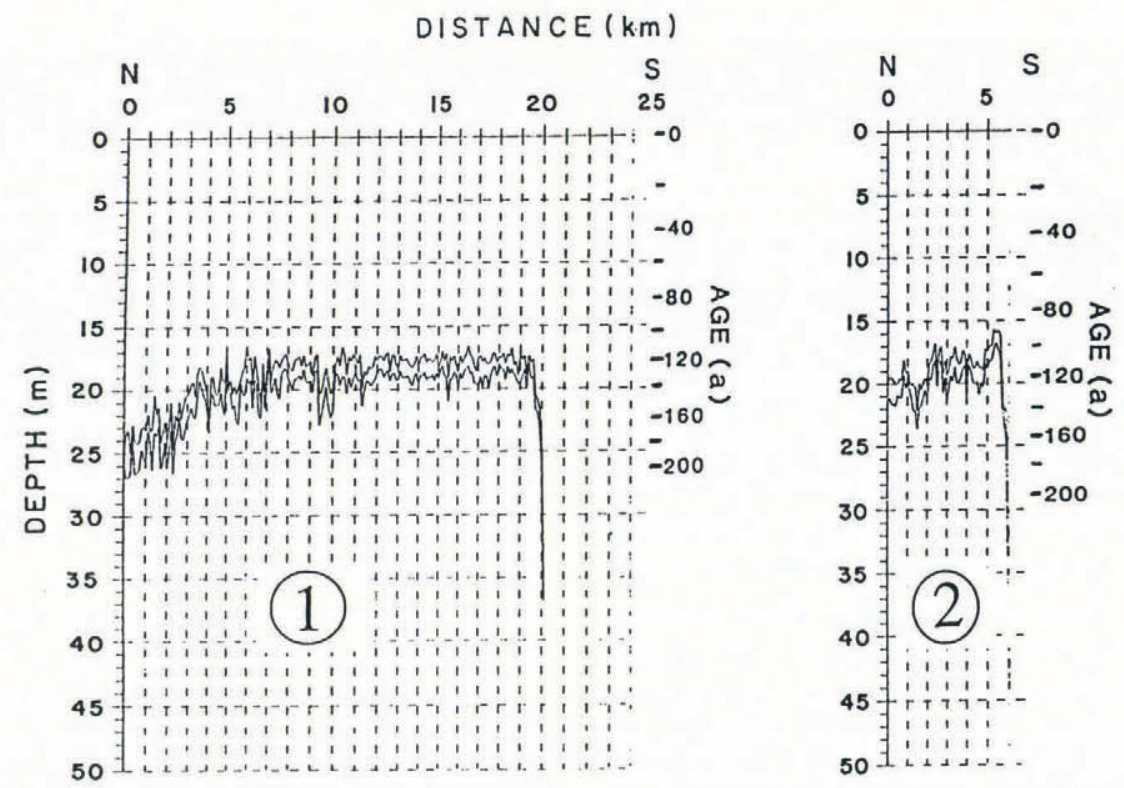

Fig. 5. Picked depths along with calculated age, for profiles 1 and 2 (labeled with large numbers) plotted against distance along the profile. Both profiles begin within the ice stream and end on Ridge BC. The direction of ice flow is out of the page. The upper and lower lines represent the deepest laterally continuous layer and the apex of the shallowest hyperbola, respectively. 
DISTANCE $(\mathrm{km})$
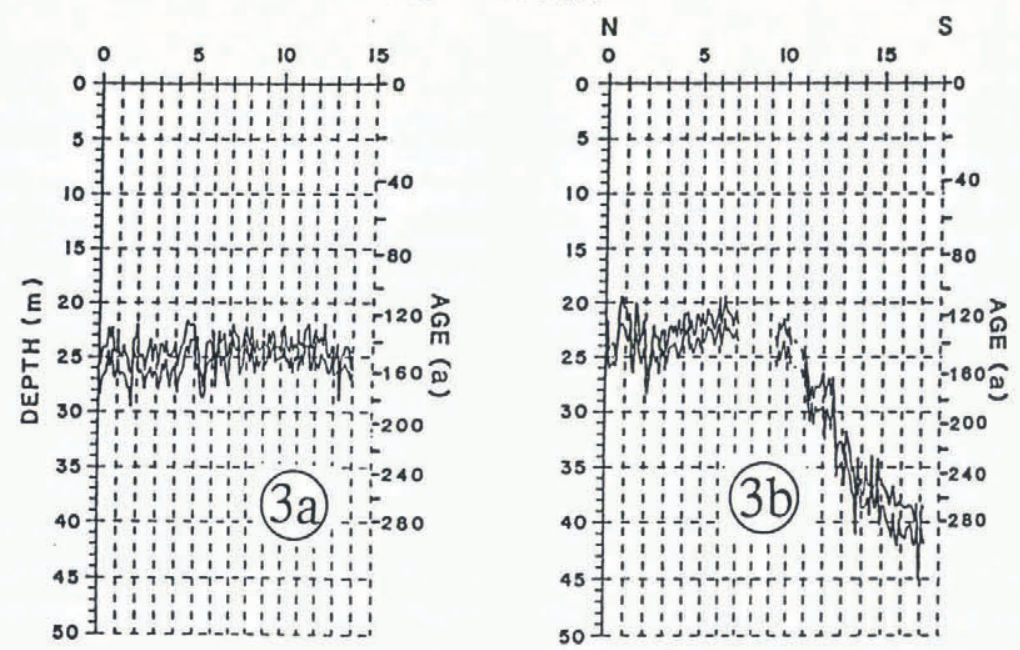

Fig. 6. Picked depths for profiles $3 a$ and $b$, along with calculated age, plotted against distance along the profile. Profile $3 a$ follows the perimeter of a rectangle near the center of the ice stream. Profile $3 b$ starts within the ice stream and ends on Ridge BC. Blank sections near the middle of the profile are data gaps. On profile $3 b$ the direction of ice flow is out of the page. For the meaning of the two lines see Figure 5.

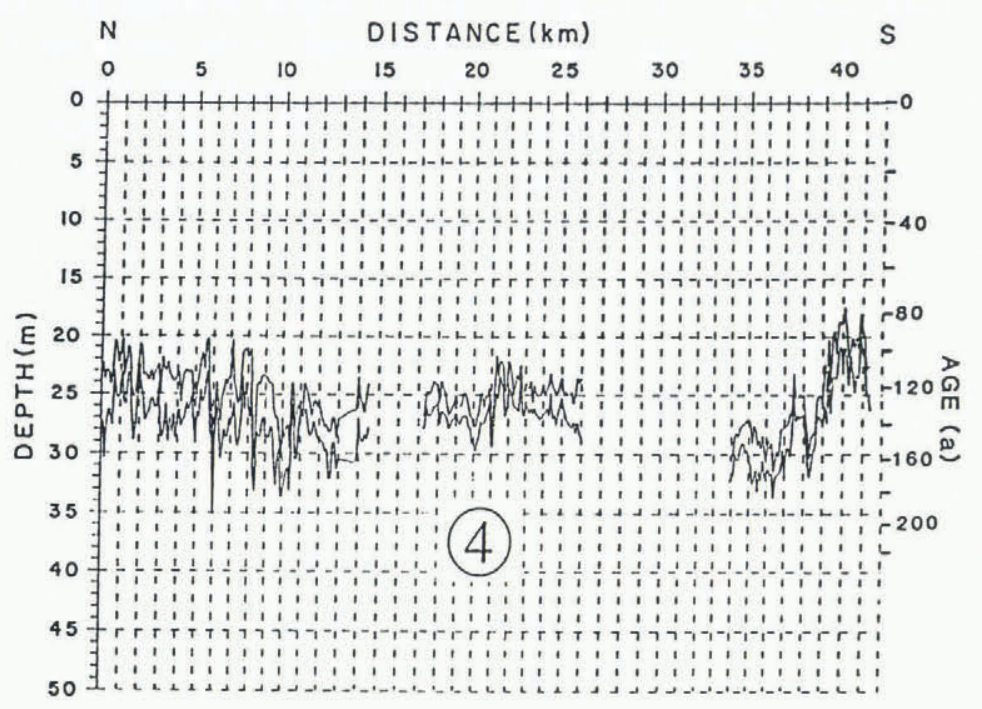

Fig. 7. Picked depths for profile 4 plotted, along with calculated age, against distance along the profile. The profile begins within the ice stream and ends on Ridge BC. Blanked areas are crevasse-free zones. The southern shear margin is the far right part. The direction of ice flow is out of the page. For the meaning of the two lines see Figure 5.

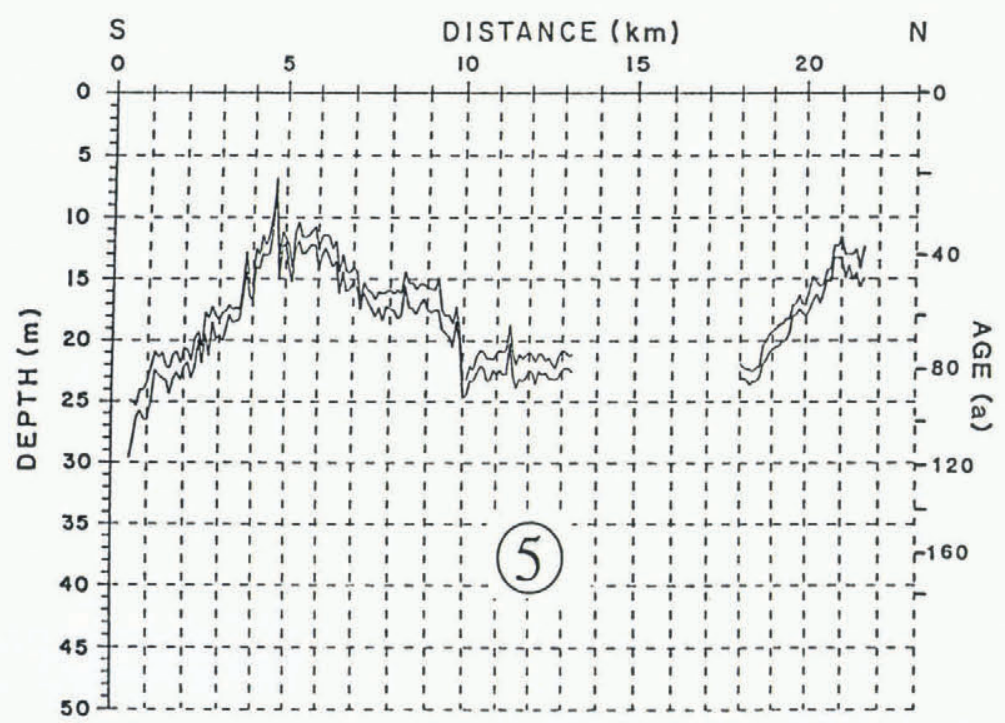

Fig. 8. Picked depths for profile 5 plotted, along with calculated age, against distance along the profile. The profile begins on Ridge $B C$ and runs to the north. Note the reversal of north and south relative to the other profiles; the direction of ice flow here is into the page. For the meaning of the two lines see Figure 5. 
crevasses were already buried before ice-stream movement ceased. The depth of $\sim 19 \mathrm{~m}$ corresponds to a stagnation age of $\sim 130$ year. The difference between the depths to the apices and to the laterally continuous layer (Fig. 5), together with the small-scale lateral variations in these depths, indicates an uncertainty in the age of \pm 15 year. (The estimated errors given for the stagnation ages in this section are only those due to the picking uncertainty. The overall error in the analysis is considered below.) A rapid increase in the burial depth occurs in the final $500 \mathrm{~m}$ of the profile.

Profile 2 (Fig. 5) is a short profile located over a narrow section of the shear margin about half-way between UpC and the downstream end of the ice stream. The profile, which clearly extends on to Ridge $\mathrm{BC}$, may have started within the shear margin. If we assume that it did, then we find an average crevasse burial depth of $\sim 19-20 \mathrm{~m}$, corresponding to a stagnation age of $\sim 120 \pm 20$ year. On the other hand, the true shear margin may begin at $2 \mathrm{~km}$ on the profile, in which case the indicated burial age is about $110 \pm 10$ year. Note that the shear margin might very well have narrowed as the ice stream slowed down. A rapid increase in the burial depth in the last $500 \mathrm{~m}$ occurs here as in profile 1 .

Profile 3 is split into parts a and b (Fig. 6). Profile $3 \mathrm{a}$ follows the perimeter of a rectangle located $1 \mathrm{~km}$ downstream of UpC camp in the central part of the ice stream. Profile $3 \mathrm{~b}$ runs linearly from a point just on the ice-stream side of the mapped shear margin on to Ridge $\mathrm{BC}$. The two gaps in profile $3 \mathrm{~b}$ around 8 and $10.5 \mathrm{~km}$ are due to poor data quality - depths could not be picked. Profile $3 a$ shows a slightly greater depth than the shearmargin part (first $7-10 \mathrm{~km}$ ) of profile $3 \mathrm{~b}$, which suggests again that the crevasses in the body of the ice stream were buried before the final stagnation of the ice stream.

The inner (first) part of profile $3 \mathrm{~b}$ shows an average burial depth of $\sim 23 \mathrm{~m}$, which corresponds to a stagnation age of $\sim 130 \pm 20$ year. In the outer part of the profile, starting at $\sim 11 \mathrm{~km}$, the crevasses show a steady, gradual increase in burial depth instead of the abrupt termination seen in profiles 1 and 2. At the end of the profile, the depth is $40 \mathrm{~m}$, which corresponds to an age of $\sim 280$ year. (The end of this profile does not represent the end of the buried crevasses but the end of profiling due to logistical constraints on the experiment.) The gradation in burial depth suggests a gradual migration of the shear margin over a period of at least 150 year. Perhaps Ice Stream C contracted in width here before it stagnated.

The burial age of 150 year on profile $3 \mathrm{a}$ is substantially younger than that the 250 year estimated by Shabtaie and Bentley (1987) from a short-pulse radar survey about $10 \mathrm{~km}$ away primarily because they used an average depth to crevasse hyperbolae, whereas we have used minimum depths. Another factor may be the difference in location. On some radargrams from the earlier work not shown by Shabtaie and Bentley (1987), the hyperbolae are only buried by about $\sim 23 \mathrm{~m}$ (personal communication from S. Shabtaie, 1992), just as on the inner part of shear-margin profile $3 \mathrm{~b}$.

Profile 4 (Fig. 7), located about $60 \mathrm{~km}$ upstream from $\mathrm{UpC}$ in a complicated transition zone crosses five distinct zones mapped by Shabtaie and Bentley (1987). The profile begins in the heavily crevassed zone in the middle of Ice Stream C (considered by Shabtaie and Bentley (1987) to be itself the downstream end of a marginal shear zone) and crosses through an undisturbed zone (15$17 \mathrm{~km}$ ), a moderately crevassed zone in the middle of the southern half of the ice stream $(17-26 \mathrm{~km})$, another undisturbed zone $(26-34 \mathrm{~km})$, and finally through the shear margin on to Ridge BC. The two crevassed zones within the ice stream have an average burial depth of $\sim 26 \mathrm{~m}$ and a stagnation age of $\sim 130 \pm 20$ year. The last section (34-41 km) can be interpreted in two ways. Either the whole section is properly the shear margin, in which case the shear margin apparently shrank in width during the last 50 year before the ice stream stagnated, or only the last $2 \mathrm{~km}(39-41 \mathrm{~km})$ represent the shear margin, in which case that margin is unusually narrow here. In either case, the final stagnation occurred $\sim 100 \pm 10$ year ago.

Profile 5 (Fig. 8), located about $200 \mathrm{~km}$ upstream of $\mathrm{UpC}$, is the only profile in which the pattern of crevasses does not conform well with the shear margin as mapped by Shabtaie and Bentley (1987). The profile, unlike the others, begins on Ridge BC. The first $12 \mathrm{~km}$ section, at a slight angle to the rest of the profile, shows only the flat horizontal layers of undisturbed ridge ice and is not shown in Figure 8 . Crevasses begin $0.5 \mathrm{~km}$ beyond the bend in the profile (the beginning of Figure 8) and continue for about $13 \mathrm{~km}$, at which point they give way to an interesting, but unexplained, angular unconformity characterized by sloping layers overlain by horizontal layering (an example is shown in Figure 9). The dip angle and direction of the sloping layers varies along the profile until about $18 \mathrm{~km}$. (The $5 \mathrm{~km}$ section with the unconformity is left blank in Figure 8.) There, hyperbolae from buried crevasses resume and continue to $21.5 \mathrm{~km}$, where flat-layered crevasse-free ice begins.

Burial depths on this profile vary between 10 and $25 \mathrm{~m}$; this large variation is not seen in the other profiles.

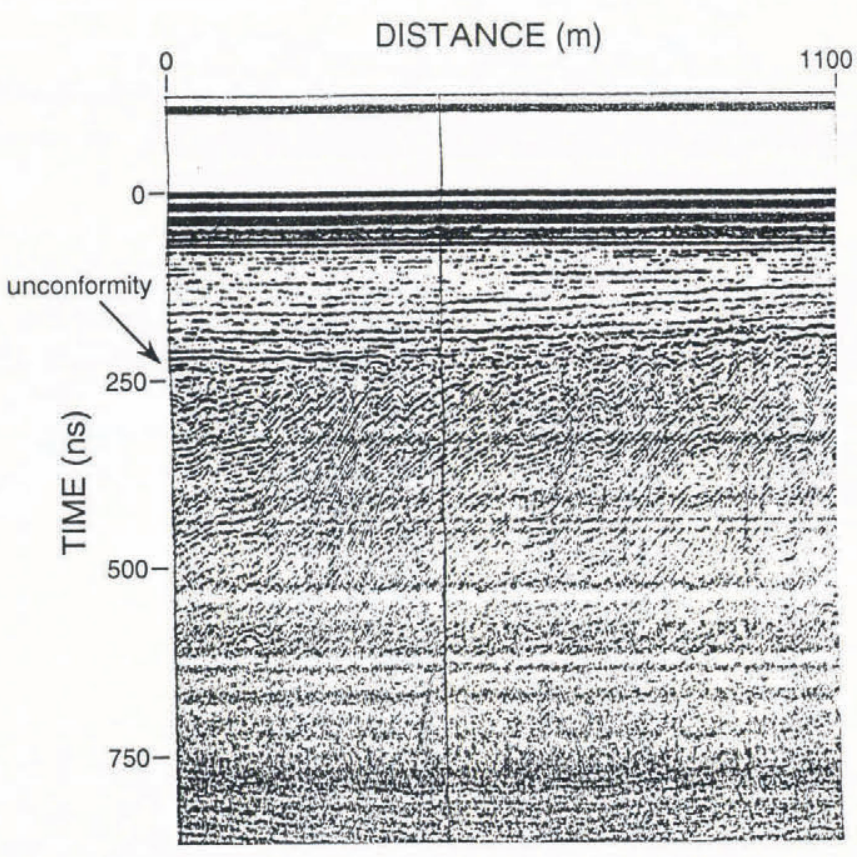

Fig. 9. Radargram of a part of profile 5 showing the unconformity that characterized the profile between 13 and $18 \mathrm{~km}$ (gap in Figure 8). 
Also, the hyperbolae are less densely spaced, more typical of crevasses within the ice stream than of those in shear margins. Nevertheless, our interpretation is that the shallowest sector, around $5 \mathrm{~km}$, was the shear margin at the time of stagnation, that the deepening crevasses in the first $4 \mathrm{~km}$ of the profile represent a lateral movement of the shear margin, and that the crevasses on the rest of the profile lay within the ice stream when it was active. The burial ages of 30-95 year are much younger than those on the other profiles. In fact, exposed surface crevasses, striking parallel to the axis of the ice stream, were sighted from the air only about $5 \mathrm{~km}$ northwest of the end of this profile, along the mapped northern margin of the ice stream.

\section{Error estimate}

Four major sources of error contribute to the overall error estimate for the stagnation ages taken from Figures 4-8.

(1) Uncertainty in picking the proper horizon on the radar records. This yields an error of $\pm 20 \mathrm{~m}$ (see discussion of individual profiles, above).

(2) Uncertainty in the density-depth curve as it affects the travel time-depth conversion. As stated earlier, the depth uncertainty from this cause is about $1 \mathrm{~m}$. Assuming an accumulation rate of $100 \mathrm{~mm}$ of ice per year and a depth of $25 \mathrm{~m}$, that translates into an age uncertainty of \pm 8 year.

(3) Uncertainty in the density-depth curve as it affects the depth-age conversions. This is estimated by taking the $\mathrm{UpB}$ core and the $\mathrm{RBC}$ core as upper and lower limits for the appropriate density-depth curve. With the same assumptions for accumulation rate and burial depth, this yields an age uncertainty of \pm 10 year.

(4) Uncertainty in the accumulation rate as it affects the depth-age conversion. For the given uncertainty of $\pm 15 \mathrm{~kg} \mathrm{~m}^{-2}$ year $^{-1}$ and the same assumptions this contributes \pm 20 year.

In combining these errors, we note first that error sources (2) and (3) are anti-correlated and of about the same magnitude, as they essentially cancel each other. For example, a higher density would imply a smaller wave velocity, so the depth for a given reflection time, and consequently the age, would decrease. On the other hand, that increase in density would imply a larger mass above a given depth, hence a greater age. Our overall error estimate, therefore, is simply the root-sum-square of error sources (1) and (4), or \pm 30 year.

\section{DISGUSSION}

It is clear from the indicated ages of stagnation that the ice stream ceased its activity rapidly, particularly in its lower reaches. From $\mathrm{UpC}$ to the Ross Ice Shelf, a distance of $250 \mathrm{~km}$, the ages are indistinguishable from each other within the 30 year uncertainty, which suggests strongly that the process of stagnation took no more than a very few decades. The entire sequence of ages implies that a disturbance has spread upstream from an initiation in the lower reaches of the ice stream. (The open crevasses could indicate a recent re-activation of the upper reaches of the ice stream but that would not explain the shallow depths of crevasse burial on profile 5.) If we compare the age at profile $5, \sim 60$ year, with that near the mouth of the ice stream, we may interpret the results as suggesting a "stopping wave" propagating $150 \mathrm{~km}$ upstream in approximately 70 year. This is in good agreement with the model results of Alley and others (1987), who calculated that a disturbance would travel up the length of a $300 \mathrm{~km}$ long ice stream in about 50 year. The field results also suggest that the speed of propagation of the disturbance has diminished with time. A slowing of the wave of disturbance as it moves upstream, where it encounters thicker, slower-moving ice and more viscous till, is another characteristic of the models of Alley and others (1987), particularly the model that includes the constraint of constant ice-thickness gradient at the head (a more realistic constraint than constant ice thickness). For example, in that model the wave takes about five times as long to travel the upper half of the ice stream as to travel the lower half. The decrease in speed suggested by our observations is similar.

The model of Alley and others (1987) was premised on the assumption that the control on ice motion is provided by the viscosity of the basal deforming till, an assumption that is strongly questioned (Kamb and Engelhardt, 1991; Whillans and Van der Veen, 1993b). How strongly the agreement between model results and observations can be taken to support the premise of the model is not clear, as response times based on other concepts of dynamic control, such as "sticky spots" (Whillans and Van der Veen, 1993b) or side drag (personal communication from I. M. Whillans, 1992) have not been calculated. Nevertheless, the likelihood that a deforming basal till plays an important role is enhanced by these results.

More important than the speed of propagation of the disturbance is an understanding of what the mechanism is that results in the stagnation of the ice stream. Here we have no direct evidence but it is our view that the speed of response implies a mechanism related to water at the bed. Alley and others (1989) have pointed out that Ice Stream $\mathrm{B}$, which we take as a model for Ice Stream $\mathrm{C}$ when it was active, generates much more basal meltwater than can be removed either by percolation through, or advection with, the subglacial mobile till. Free water must be distributed in some way on the ice-bed interface; according to Alley (1989), a relatively uniform sheet would be the stable configuration and it would increase in thickness downstream. Indeed, a layer 1 or $2 \mathrm{~mm}$ thick actually has been found under Ice Stream B (Kamb and Engelhardt, 1991). But, according to Walder (1982), such a layer on an impermeable bed would be unstable, if it were more than a few millimeters thick, in the sense that thicker parts would grow at the expense of thinner ones. If this could happen beneath an ice stream, perhaps it could lead to a channel system in which water pressures would drop, thus leading to a draining of water from the dilated till.

Alley (1989) has calculated that such channels should not form on a deforming bed because the soft sediment would be squeezed into and fill the channels. However, a water layer more than a few millimeters thick would tend 
to decouple the ice stream from its bed; this might decrease the stirring action of the ice on the bed enough to allow it to lose its dilatancy, at least in its uppermost part, and stiffen to the point that it would not interfere with the growth of the channels.

Such a process should start at the lower end of the ice stream, because that is where the basal water layer would be thickest and hence the most likely to become unstable. As Röthlisberger channels (Röthlisberger, 1972) formed and water pressures dropped, the water would tend to drain from the till, thereby further reducing its dilatancy and greatly increasing the basal drag on the ice stream. A stiffer bed with an ample supply of basal water coming from melting beneath the still active higher segment of the ice stream would further promote the development of Röthlisberger channels which would thus propagate upstream, causing a wave of ice-stream stagnation.

A difficulty with this concept might seem to arise from the extremely low permeability of the deforming till - on the order of $10^{-8}-10^{-9} \mathrm{~m} \mathrm{~s}^{-1}$ at UpB (Engelhardt and others, 1990). However, the development of water channels would involve a substantial drop in water pressure that would act over short distances in the till to cause dewatering rather quickly. For example, a drop in hydraulic head of $10 \mathrm{~m}$, only $1 \%$ of the glacio-isostatic pressure, would establish a head gradient over a few meters distance in the till sufficient to produce a flow rate through the till of the order of $1 \mathrm{~m} \mathrm{year}^{-1}$. Furthermore, the bed might stiffen to deformation simply from the loss of water pressure itself, without the need for extensive dewatering.

Our hypothesis for the stagnation process implies that the speed with which the "stagnation front" moves upstream is related to the speeds of the till dewatering (or depressurization) and channel formation. Although we have no quantitative model as yet, we can at least say that in principal both processes could proceed rapidly enough to explain our observations. It is hard to see how other potential causes that have been suggested, such as thinning of the deforming till by subglacial transport, loss of water from the till into a subjacent aquifer or capture of ice and/or subglacial water by neighboring ice streams, could be effectuated so rapidly. Capture hypotheses have the additional disadvantage of implying initiation from the head of the ice stream, contrary to the evidence presented here.

If our concept is correct, it further implies that stagnation might be the natural fate of any ice stream that developed too large a flow of subglacial water near its mouth. A cycle can be envisaged in which an ice stream accelerates by increasing its mass flux, consequently increasing basal melting until subglacial sheet flow of water at its mouth is no longer stable and the ice stream stagnates. Its drainage basin could then be captured by an adjacent ice stream that would repeat the cycle.

\section{GONGLUSIONS}

The shear-margin experiment revealed no measurable difference in the stagnation age of the lower $250 \mathrm{~km}$ of Ice Stream C. The three profiles farthest downstream give a stagnation age of $130 \pm 30$ year. The profile $60 \mathrm{~km}$ upstream from UpC exhibits a suggestively younger age of $100 \pm 30$ year. The most upstream profile, located about $200 \mathrm{~km}$ upstream of UpC, yields stagnation ages that range from only 30 to 100 year, substantially and significantly less than those of the other profiles. Recent activity is also indicated by the existence of an open crevasse nearby.

We believe this pattern is best explained by a "wave" of stagnation that started at or near the downstream end of the ice stream and propagated upstream at a speed that decreased with time. We suggest that stagnation occurred because the subglacial water flow became too great to remain stable as sheet flow $-\mathbf{R}$ channels developed that led to a drop in water pressure, which in turn caused dewatering of the subglacial deforming till, thus immobilizing it. Upstream migration of the $\mathrm{R}$ channels led to upstream propagation of the stagnation "front".

\section{ACKNOWLEDGEMENTS}

We are particularly indebted to I.M. Whillans and G. Casassa of the Byrd Polar Research Institute, The Ohio State University, for providing the ground-station coordinates that we used for control, and to S. Shabtaie for a wealth of unpublished information. The skill and cooperativeness shown by R. Allen and crew, of Ken Borek Air, was invaluable in making the flight program a success. Helpful field assistance was also provided by $\mathrm{S}$. Anandakrishnan, S. Atre, C. Munson and A. Novick. We thank R. W. Jacobel, D. R. MacAyeal and an anonymous referee for comments that led to substantial improvements in the paper. This research was supported by U.S. National Science Foundation grant DPP86-14011. This is Contribution No. 524 of the University of WisconsinMadison, Geophysical and Polar Research Center.

\section{REFERENGES}

Alley, R.B. 1989. Water-pressure coupling of sliding and bed deformation: I. Water system. F. Glaciol., 35(119), 108-118.

Alley, R. B. and C. R. Bentley. 1988. Ice-core analysis on the Siple Coast of West Antarctica. Ann. Glaciol., 11, 1-7.

Alley, R. B., D. D. Blankenship, S. T. Rooney and C. R. Bentley. 1987. Till beneath Ice Stream B. 4. A coupled ice-till flow model. J. Geophys. Res., 92(B9), 8931-8940.

Alley, R. B., D. D. Blankenship, S. T. Rooney and C. R. Bentley. 1989. Water-pressure coupling of sliding and bed formation: III. Application to Ice Stream B, Antarctica. J. Glaciol., 35(119), 130139.

Bentley, G. R., S. Shabtaie, D. G. Schultz and S. T. Rooney. 1985. Continuation of glaciogeophysical survey of the interior Ross Embayment: summary of 1984-1985 field work. Antarct. F. U.S., 20(5), 63-64.

Clausen, H. B., W. Dansgaard, J. Nielson and J. W. Clough. 1979. The surface accumulation on the Ross Ice Shelf. Antarct. F. U.S., 14(5), 68-72.

Crary, A. P. and C. R. Wilson. 1961. Formation of "blue" glacier ice by horizontal compressive forces. J. Glaciol., 3(30), 1045-1050.

Engelhardt, H., N. Humphrey, B. Kamb and M. Fahnestock. 1990. Physical conditions at the base of a fast moving Antarctic ice stream. Science, 248(4951), 57-59.

Kamb, B. and H. Engelhardt. 1991. Antarctic Ice Stream B: conditions controlling its motion and interactions with the climate system. International Association of Hydrological Sciences Publication 208 (Symposium at St. Petersburg 1990 - Glaciers-Ocean-Atmosphere Interactions), $145-154$. 
Kirchner, J. F., C. R. Bentley and J. D. Robertson. 1979. Lateral density differences from seismic measurements at a site on the Ross Ice Shelf, Antarctica. F. Glaciol., 24(90), 309-312.

Kohnen, H. 1972. Über die Beziehung zwischen seismischen Geschwindigkeiten und der Dichte in Firn und Eis. Z. Geophys., 38(5), 925-935.

Looyenga, H. 1965. Dielectric constants of heterogeneous mixtures. Physica, 31(3), 401-406.

Robin, G.de Q, S. Evans, D.J. Drewry, C.H. Harrison and D.L. Petrie. 1970. Radio-echo sounding of the Antarctic ice sheet. Antarct. J. U.S., 5(6), 229-232.

Rose, K.E. 1979. Characteristics of ice flow in Marie Byrd Land, Antarctica. 7. Glaciol., 24(90), 63-75.

Röthlisberger, H. 1972. Water pressure in intra- and subglacial channels. F. Glaciol., 11(62), 177-203.

Shabtaie, S. and C.R. Bentley. 1987. West Antarctic ice streams draining into the Ross Ice Shelf: configuration and mass balance. $\mathcal{F}$. Geophys. Res., 92(B2), 1311-1336.

Shabtaie, S. and C. R. Bentley. 1988. Ice-thickness map of the West Antarctic ice streams by radar sounding. Ann. Glaciol., 11, 126-136.
Walder, J.S. 1982. Stability of sheet flow of water beneath temperate glaciers and implications for glacier surging. F. Glaciol., 28(99), 273293.

Whillans, I.M. and R.A. Bindschadler. 1988. Mass balance of Ice Stream B, West Antarctica. Ann. Glaciol., 11, 187-193.

Whillans, I. M. and C.J. van der Veen. 1993a. New and improved determinations of velocity of Ice Streams B and C, West Antarctica. f. Glaciol., 39(133), 483-490.

Whillans, I. M. and C.J. van der Veen. 1993b. Patterns of calculated basal drag on Ice Streams B and C, Antarctica. F. Glaciol., 39(133), 437-446.

Whillans, I. M., J. Bolzan and S. Shabtaie. 1987. Velocity of Ice Streams B and C, Antarctica. 7. Geophys. Res., 92(B9), 8895-8902.

The accuracy of references in the text and in this list is the responsibility of the authors, to whom queries should be addressed. 